\title{
Justiça como Equidade e o Problema da Razoabilidade
}

\author{
Denis Coitinho Silveira \\ deniscoitinhosilveira@gmail.com \\ Universidade do Vale dos Sinos (UNISINOS), São Leopoldo, Brasil
}

resumo Neste artigo eu quero mostrar a importância do conceito de razoável na teoria da justiça como equidade, de John Rawls e, também, quero explicar o problema da razoabilidade nessa teoria. 0 ponto de partida será ressaltar a exigência de razoabilidade que é feita ao agente moral na justiça como equidade. Posteriormente, procurarei identificar algumas críticas a esse critério. Partirei da crítica formulada por Estlund a respeito do estreitamento do conceito de razoabilidade e a necessidade da verdade e das críticas estabelecidas por Timmons e Gaus sobre a exigência demasiada e ineficaz da razoabilidade. 0 passo seguinte será tentar responder a essas críticas formuladas e, na parte final do texto, procurarei estipular um argumento a respeito de um tipo de responsabilidade moral razoável que pode estar contida na justiça como equidade.

palavras-chave Equidade; Razoabilidade; Limites da razão; Limites do juízo; Responsabilidade; Rawls

Qual é a exigência adequada que se pode fazer a um agente moral? Que ele saiba todos os critérios morais, como princípios e virtudes, que devem ser aplicados ao caso, de forma que ele conheça esse critério como verdadeiro, isto é, correspondente a um certo estado de coisas? Ou, alternativamente, bastará que ele oriente sua ação a partir de suas convicções morais mais profundas? O que uma teoria normativa pode exigir factivelmente de um sujeito moral, de forma que essa exigência seja eficiente, isto é, que 
ela realmente obrigue o sujeito a fazer a ação X ou Y? Ela pode exigir o conhecimento de um critério último de justificação das crenças morais, bem como de um ponto arquimediano, ou ela apenas pode sugerir que o sujeito revise suas convicções quando em uma situação de conflito? Qual seria a dose adequada de exigência?

Como se pode facilmente perceber, as respostas dadas às questões anteriormente formuladas ou recaem sob um modelo fundacionalista de justificação ou sob um modelo epistêmico-moral contextualista. Mas, será que nossas opções se restringem apenas a essas duas? Não seria possível encontrar um modelo intermediário que nem exigisse do agente o conhecimento último do critério moral e nem se contentasse apenas com a revisibilidade de suas crenças? Creio que podemos encontrar essa posição intermediária na teoria da justiça como equidade de John Rawls. O argumento central dessa teoria parece ser o de que, de um ponto de vista social (social point of view), se pode chegar a um consenso do que contará como tendo um valor moral público de uma forma independente das crenças privadas de bem, de forma que se vão construir princípios morais políticos (de igual liberdade, igualdade equitativa de oportunidade e diferença) a partir dos próprios valores morais reconhecidos socialmente em uma sociedade democrática do tipo contemporânea e, então, a estratégia será testá-los por (i) sua coerência com os pontos fixos dos juízos morais ponderados (considered judgments) em todos os níveis de generalidade e (ii) por seu resultado quando aplicado às instituições democráticas, isto é, por sua garantia de estabilidade pelas razões corretas (stability for the right reasons) que conduz à legitimidade política (political legitimacy), o que é outra forma de dizer que eles serão testados por um equilíbrio reflexivo (reflective equilibrium) amplo (wide) e geral (general), sendo a justificação concebida em um equilíbrio reflexivo pleno $(f u l l)^{1}$.

O ponto de partida, então, é o que já é aceitável socialmente, isto é, os próprios valores morais políticos que são assumidos pelos cidadãos de uma democracia contemporânea, tais como: razoabilidade, reciprocidade, tolerância, civilidade, cooperação etc., valores esses que serão usados no procedimento de construção da posição original (original position. Isto é demonstrado pelo papel central que a ideia normativa de sociedade como um sistema equitativo de cooperação social desempenha no procedimento, que implica nas ideias normativas de pessoas como livres e iguais e 
sociedade bem ordenada, ideias essas que estarão pressupostas no procedimento de deliberação das partes (parties) sob as restrições do véu da ignorância (veil of ignorance) e circunstâncias da justiça (circumstances of justice) para a construção/escolha dos princípios morais e o teste pelo equilíbrio reflexivo. Nas palavras de Rawls:

Reunimos as convicções arraigadas, como a crença em tolerância religiosa e a rejeição da escravidão e tentamos organizar as ideias e princípios básicos implícitos nessas convicções numa concepção política de justiça coerente. Tais conviç̧ões são pontos fixos provisórios que parece que qualquer concepção razoável deve levar em conta. Começamos, então, observando a própria cultura pública como fundo compartilhado de ideais e princípios básicos implicitamente reconhecidos. (RAWLS, 1996, p. 8)².

Veja-se que o que essa teoria normativa exige do sujeito moral será uma disposição de propor e cumprir os termos equitativos de cooperação, como já vimos anteriormente e, também, uma disposição para reconhecer os limites da razão em justificar arquimedianamente os juízos morais proferidos pelos indivíduos, isto é, ela exigirá o reconhecimento da sobrecarga da razão (burdens of reasons), o que é uma outra forma de dizer que ela exigirá que o sujeito moral seja razoável (reasonable). Mas, o que isso significa? Que o sujeito deve se dispor a partir da ideia de sociedade equitativa para o estabelecimento do critério moral público porque já faz uso da ideia de reciprocidade. Que ele deve se dispor a reconhecer o fato do pluralismo razoável e o fato da opressão, que é igual a reconhecer a existência de várias convicções morais sobre o bem em sociedades complexas contemporâneas como uma característica permanente e, também, que a única forma de alcançar uma unidade moral absoluta seria pelo uso da força do Estado para obrigar todos os sujeitos a aceitar uma mesma concepção de bem³ ${ }^{3}$. Esse parece ser um posicionamento de aceitação da falibilidade humana em alcançar a justificação absoluta de suas crenças morais e, por isso, não exige do sujeito moral o conhecimento do critério último de justificação, isto é, sua verdade. Antes, trata-se de uma tentativa de aplicar o conceito de tolerância à própria filosofia moral. Dessa forma, a razão é deflacionada, no sentido que ela terá uma capacidade limitada para alcançar a justificação. A exigência de razoabilidade (reasonableness) é explicada nesses termos por Rawls: 
O primeiro aspecto básico do razoável é, portanto, a disposição de propor termos equitativos de cooperação e cumpri-los, desde que os outros também o façam. O segundo aspecto básico, como agora revejo, é a disposição de reconhecer os limites do juízo e aceitar suas consequências para o uso da razão pública na condução do exercício legítimo do poder político em um regime constitucional (RAWLS, 1996 , p. 54) ${ }^{4}$.

Por ser uma disposição, a ação razoável ou a razoabilidade está sendo tomada como uma virtude necessária ao agente moral para sua deliberação, pois exigirá do agente uma disposição moral de agir a partir do critério de reciprocidade e uma disposição intelectual de reconhecimento da limitação racional. Por outro lado, é importante frisar que a justiça como equidade não se contentará com apenas uma exigência mínima de revisibilidade das crenças por parte do indivíduo, embora essa característica seja de fundamental importância nesse modelo coerentista holístico e pragmatista de justificação. É por esse motivo que os procedimentos ocupam um papel central para a justificação da norma, de forma a exigir, também, o reconhecimento de determinados fatos que podem contar como razões no procedimento ou da posição original - equilíbrio reflexivo ou do consenso sobreposto (overlapping consensus). Mas, que fatos contam como uma razão no procedimento? As crenças que são justificadas intersubjetivamente, isto é, que podem ser tomadas como fatos sociais (institucionais). Por exemplo: que a cooperação é boa socialmente, que as pessoas são morais, isto é, livres e iguais, que a exigência de reciprocidade é uma boa medida para a resolução de conflitos. Esses fatos não dependem da aprovação de um indivíduo isolado, mas requerem uma aprovação social que, inclusive, pode ser percebida em uma dimensão histórica ${ }^{5}$.

Procurei mostrar acima como o critério de razoabilidade parece central para o projeto de Rawls. Mas, pode uma teoria normativa de justiça prescindir do conceito de verdade para a justificação, contentando-se apenas com o critério de razoável? Não se perderia toda a normatividade com esse movimento e a recaída no relativismo seria inevitável? Ou, alternativamente, não seria demasiado e ineficaz exigir a razoabilidade do agente moral, uma vez que exigiria um tipo de conhecimento que o agente moral comum não tem acesso ou, no limite, que as pessoas são absolutistas 
e não razoáveis em seus juízos cotidianos? No restante desse artigo procurarei responder a essas questões. Partirei da crítica formulada por Estlund a respeito do estreitamento do conceito de razoabilidade e a necessidade da verdade e das críticas estabelecidas por Timmons e Gaus a respeito da exigência demasiada e ineficaz da razoabilidade. Posteriormente, tentarei responder a essas críticas formuladas e, na parte final do texto, procurarei formular um argumento a respeito de um tipo de responsabilidade moral razoável que pode estar contida na justiça como equidade.

\section{II}

Deixem-me iniciar com a crítica de Estlund feita no artigo "The Insularity of the Reasonable", que afirma que a justiça como equidade deve admitir a verdade, sendo o critério de razoabilidade ou aceitabilidade limitado para garantir a justificação dos princípios morais em razão de seu modelo de legitimação não ser defensável por sua incompletude. Isso porque a tese central do Liberalismo Político é afirmar princípios morais políticos de tolerância no âmbito da justificação pública que não precisam ser verdadeiros. Isso implica que mesmo doutrinas verdadeiras são inadmissíveis a menos que elas sejam aceitas por todos os cidadãos razoáveis. Estlund vê acertadamente, então, que a verdade não é nem condição necessária e nem suficiente para a admissibilidade das doutrinas abrangentes:

A ideia moral por trás desse princípio é que nenhuma pessoa pode legitimamente ser coagida ou moralmente obrigada a seguir normas legais e obrigações a menos que razões suficientes possam ser dadas que não violem as convicções morais e filosóficas razoáveis das pessoas sobre o verdadeiro ou falso, certo ou errado. (ESTLUND, 1998, p. 253).

$\mathrm{O}$ argumento que Estlund parece defender é que se esse princípio sobre justificação é ele próprio oferecido como parte da justificação pública, ele, então, se aplica a si mesmo. Segue daí que ele deve ser aceitável para todos os cidadãos razoáveis e não pode ser invocado como verdadeiro, nem mesmo a própria concepção de razoabilidade. A tese parece afirmar que esse modelo de justificação pública deve afirmar a verdade e não apenas a razoabilidade de seu princípio fundamental, a saber, a ideia de que 
doutrinas são admissíveis como premissas na justificação pública somente se forem aceitáveis para todos os cidadãos razoáveis. Embora um tanto diferente da crítica já bem conhecida feita por Raz, em razão de fazer uma conexão correta entre justificação e legitimidade, também afirmará que uma teoria política normativa não pode pairar acima da verdade moral, sem qualquer ponto de contato ${ }^{6}$.

Seu argumento central é apresentado com a seguinte formulação intitulada de RAN (Reasonable Acceptance Necessary): "Nenhuma doutrina é admissível como uma premissa em qualquer estágio da justificação política a menos que ela seja aceitável para todos os cidadãos razoáveis, e não necessita ser aceitável para mais ninguém." (ESTLUND, 1998, p. 254). Entendendo o termo "doutrina” de forma a significar declarações factuais, princípios, propostas e mesmo juízos morais, RAN, assim, é ela própria uma doutrina. A questão, então, é a de que essa doutrina não precisa ser verdadeira, mas apenas aceitável por todos. A crítica de Estlund é que a razoabilidade, que é a aceitabilidade de todos, deve ela própria ser verdadeira, ou, então, essa doutrina seria arbitrária e os indivíduos não precisariam se ver obrigados a segui-la. O problema aqui é que RAN é aplicada a ela mesma, sendo ela própria uma premissa na justificação pública. O ponto central nessa argumentação é mostrar que Rawls deveria considerar a questão de que seu princípio liberal de legitimidade deveria ser tomado como verdadeiro. Sumarizando o argumento de Estlund até o momento, temos: dado que Rawls quer aplicar o princípio da tolerância à própria filosofia, a justiça como equidade aplica o princípio de tolerância nela própria e, dessa forma, deveria afirmar o requisito de tolerância também como verdadeiro. A conclusão é a de que uma concepção política alternativa de justiça, ao reivindicar sua verdade, seria substantiva e, logo, não dogmática (ESTLUND, 1998, p. 256).

O próximo passo será o da apresentação de uma versão modificada de RAN, com o interesse de investigar a questão independentemente do conteúdo da ideia de razoabilidade. Assim, AN (Acceptance Necessary): "Nenhuma doutrina é admissível como premissa em qualquer estágio da justificação política a menos que ela seja aceitável por um certo conjunto de cidadãos (reais ou hipotéticos), C, e nada mais que a aceitação é necessário." (ESTLUND, 1998, p. 257). Aqui o ponto será o de mostrar que AN afirma uma condição necessária, mas que não é suficiente para 
a admissibilidade. Como Rawls sustenta que a razoabilidade é suficiente para a justificação, evitando a pretensão de verdade, o problema é que quando uma certa versão de $\mathrm{C}$ é posta à frente de outras versões alternativas possíveis em $\mathrm{AN}$, parece não haver critérios seguros para sustentar que essa seja uma versão correta de C.A conclusão parece clara: não é possível uma escolha não arbitrária dos possíveis conteúdos de $\mathrm{C}$ nas relações entre este e as diferentes instâncias de AN que não viole sob algum aspecto a pretensão da não necessidade da verdade para a justificação pública (ESTLUND, 1998, p. 261-263).

A proposta de Estlund é a de que a teoria de Rawls deve tomar RAN como verdadeira, estabelecendo contato com a verdade, ao menos em um sentido mínimo. O critério deve ser modificado da seguinte forma: MAC (Modified Acceptance Criterion):

Como exceção dessa doutrina, nenhuma doutrina é admissível ou excluída como uma premissa na justificação política sobre as bases de sua verdade ou falsidade, mas é admissível apenas quando e porque ela é aceitável para todos os cidadãos razoáveis (...). A presente doutrina deve ser aceitável para todos os cidadãos e verdadeira. (ESTLUND, 1998, p. 266).

É importante procurar compreender qual é mudança realizada aqui.Vejase que o critério de aceitabilidade/razoabilidade continua como uma condição necessária para a justificação pública, pois o que vai justificar qualquer doutrina abrangente é sua aceitabilidade social. Por outro lado, essa doutrina da aceitabilidade deve ser ela própria aceitável e verdadeira; sendo ela verdadeira, então, também é condição suficiente para a justificação. Com a afirmação da verdade dessa premissa liberal, então, juízos morais razoáveis podem ser tomados como verdadeiros. O que Estlund parece ter em mente é que a noção de verdade que deve ser utilizada não pode ir além de um sentido mínimo: "Para qualquer declaração $\mathrm{P}$, P é verdadeiro no sentido mínimo se e somente se P". Por exemplo, se todos podem aceitar que assassinar é errado, então, "assassinar é errado" é verdadeiro no sentido mínimo requerido pelo liberalismo político. A conclusão a que ele chega é a seguinte: para uma teoria da legitimação ser defensável, ela precisa ir além dessa dimensão prática de aceitabilidade como critério de justificação e refletir e posicionar-se sobre sua verdade (ESTLUND, 1998, p. 270-275) ${ }^{7}$. 
Mas há, também, um outro tipo de crítica ao papel do critério de razoabilidade na justiça como equidade que acentua, não a sua fraqueza, mas a sua excessividade. Essa é a constatação central de Timmons, a saber, que teorias morais ao estilo da proposta por Rawls exigem em demasia do agente moral, pois exigem uma disposição para o reconhecimento dos limites da razão. Alternativamente, ele situará a responsabilidade do agente em um âmbito mais modesto, que será o de (i) obter evidência, (ii) lidar e considerar as possibilidades alternativas e (iii) lidar com conflitos internos de crenças (TIMMONS, 2004, p. 195) ${ }^{8}$.

Vejam-se as razões disso.Timmons está comprometido com um modelo de epistemologia moral contextualista, propondo uma justificação doxástica da crença moral, uma vez que a maior parte das crenças éticas comuns podem ser justificadas pela responsabilidade epistêmica do agente, o que implica em avaliar as situações alternativas. Sua tese central é que se pode ser responsável epistemicamente em assegurar certas crenças sem necessitar de justificação para elas, bastando a avaliação das crenças de primeira ordem por parte do agente, o que envolve parâmetros variáveis como: objetivo, perspectiva e recursos. Para ele, não é necessário estar engajado em uma aceitação de uma teoria moral para um indivíduo estar doxasticamente justificado em assegurar uma crença moral particular. Ao contrário, defende que as crenças doxasticamente justificadas devem ser justificadas proposicionalmente por um indivíduo, o que não implica assumir que essa justificação se dará pela coerência com um princípio moral. O problema desse modelo coerentista, como o de Rawls, é que ele não se encaixa com as deliberações morais cotidianas, pois os indivíduos não escolhem princípios entre teorias morais primeiro para só depois verificar se suas crenças estão corretas. Dessa forma, a regra da responsabilidade epistêmica contextualista é formulada da seguinte maneira por Timmons:

Normalmente, uma pessoa S é responsável epistemicamente em acreditar em algumas proposições $\mathrm{p}$ ao tempo $\mathrm{t}$ apenas se $\mathrm{S}$ checar todas as possibilidades alternativas que seriamente estão indicadas por um adequado conjunto de crenças de fundo em t. (TIMMONS, 2004, p. 200). Qual é o problema aqui? A questão é que Timmons está se contrapondo ao coerentismo que exige que o agente possua uma bateria muito grande de crenças: crenças de primeira ordem, tanto crenças morais como não morais, e crenças de segunda ordem, que são crenças para a justificação das 
primeiras. Sua proposta se pretende menos exigente, uma vez que defende o conservadorismo das crenças de segunda ordem sobre as crenças contextualmente básicas, sendo as crenças de primeira ordem justificadas se asseguradas responsavelmente pelo agente. Assim, algumas crenças morais, especialmente as que são parte constitutiva de nossa perspectiva moral, servem como um corpo de assunções morais básicas que, em contextos comuns de pensamento e discussão moral, não precisam de justificação (TIMMONS, 2004, p. 213).

$\mathrm{Na}$ justiça como equidade, o reconhecimento dos limites racionais, que é o mesmo que razoabilidade, se constitui como crenças de segunda ordem que terão o papel de julgar a validade das crenças de primeira ordem. Como a legitimidade da coerção do poder político é dada pela aceitabilidade das crenças feitas por pessoas razoáveis, a legitimidade é alcançada pela razoabilidade/aceitabilidade, sendo ela o próprio critério de justificação. Um problema que poderia estar relacionado com a crítica de Timmons de uma exigência demasiada seria o de questionar se as pessoas não razoáveis teriam a sua autonomia política desrespeitada pelo método de legitimação/justificação de Rawls? Será que a justiça como equidade não infringiria os direitos básicos e liberdades dos indivíduos não razoáveis? Seria isto justo, uma vez que no mundo real as pessoas geralmente não são razoáveis??

A constatação de que as pessoas não são de fato razoáveis pode servir, também, para ressaltar a ineficiência do critério de razoabilidade para a justificação. Esse parece ser o argumento apresentado por Gaus ao estabelecer uma crítica à ideia de justificação pública de Rawls, que estaria baseada no critério de razoabilidade, implicando em uma teoria populista do raciocínio prático, pois deve contar com um assentimento das pessoas para a justificação (GAUS, 1996, p. 130-131). Qual a estratégia empregada por Gaus? Parece ser a de mostrar a fraqueza desse critério de razoabilidade, que indicaria uma disposição para propor e seguir os princípios que podem ser publicamente justificados; para reconhecer os limites do juízo; para raciocinar corretamente; para fazer raciocínios acessíveis aos outros, fazendo uso de argumentos de bom senso e conclusões não controversas da ciência. O problema é que, para Gaus, as pessoas não são razoáveis, apresentando três razões para comprovar sua tese: (i) falácia do jogador, que mostra que as pessoas podem ser induzidas a abandonar 
normas válidas de inferência e cometer erros em juízos probabilísticos; (ii) akrasia epistêmica, que revela que as pessoas não tem disposição para aceitar os argumentos de bom senso e as provas científicas; (iii) juízos absolutistas, que aponta que as pessoas geralmente proferem seus juízos com certeza absoluta, o que não encaixa com a exigência dos limites dos juízos e com a condição de acessibilidade ${ }^{10}$. Os três exemplos revelam um mesmo argumento: as pessoas reais não são razoáveis no seu cotidiano, logo, a razoabilidade não é suficiente para a justificação, devendo ser substituída pela racionalidade, colocando a vitória de uma crença sobre outra no lugar do acordo (GAUS, 1996, p. 131-136).

\section{III}

Agora, procurarei responder a essas objeções. A respeito da crítica de Estlund sobre a necessidade do critério de razoabilidade ser verdadeiro a fim de resultar em uma concepção de legitimação adequada, inicio ressaltando uma característica central do modelo de justificação defendido por Rawls: ele quer superar os modelos dicotômicos em filosofia moral que estabelecem uma distinção radical entre uma esfera factual e outra normativa, procurando estabelecer uma relação de complementaridade entre valores e fatos, o que fica evidenciado pelo papel do método do equilíbrio reflexivo, que tem a tarefa de organizar nossos juízos morais ponderados de forma a servirem de base para a construção dos princípios, o que possibilita uma concepção moral coerente (RAWLS, 1971, p. 579; RAWLS, 1999, p. 507). Após essa observação geral, gostaria de precisar o que eu estou dizendo: que a tentativa de Rawls de superação da dicotomia fato/ valor o levará a adotar uma estratégia pragmatista de justificação - justificação é uma questão prática antes que teórica. Assim, a própria noção de razoabilidade dentro da justiça como equidade tem, ela própria, uma dimensão prática e não teórica, isto é, ela não é tomada como um critério último que estaria descolado de toda a realidade, mas, preferencialmente é um ideal político e, por essa razão, é estipulada como condição necessária e suficiente para a justificação. Nas palavras de Rawls:

Observe que aqui ser razoável não é uma ideia epistemológica (embora tenha elementos epistemológicos). Preferencialmente, ela é parte de 
um ideal político de cidadania democrática que inclui a ideia de razão pública (RAWLS, 1996, p. 62) ${ }^{11}$.

Veja-se que a crítica de Estlund é que a razoabilidade não poderia ser uma condição suficiente para justificação, sendo apenas condição necessária, uma vez que garantir a legitimidade pela pura aceitabilidade poderia recair em arbitrariedade. Por isso, sua proposta é a de tomar esse princípio da aceitabilidade como minimamente verdadeiro, na forma "Para qualquer declaração P, P é verdadeiro se e somente se P". Mas, essa acusação é procedente? Creio que não. E a razão para defender essa posição é que o critério de razoabilidade, mesmo não sendo verdadeiro, serve para a justificação pública, o que implicará na afirmação de valores morais-políticos de forma freestanding, isto é, valores que se sustentam sozinhos na esfera política, por meio do procedimento da posição original, que é normativo.Veja-se que esses valores são tomados como aquilo que é assumido socialmente, ou, dito de outra forma, esses valores proporcionam uma "base satisfatoriamente compartilhada de justificação pública."12 (RAWLS, 1989, p. 485).

Essa estratégia pode ser vista como uma tentativa de procurar estabelecer o valor em coerência com o fato, isto é, de relacionar os valores morais-políticos com as práticas sociais, políticas e econômicas de sociedades democráticas contemporâneas com diversidade moral. É por isso que para estabelecer a justificação dos princípios de justiça se precisará de uma justificação pública, o que implicará em ver se eles garantirão estabilidade social e legitimidade política. Aqui a tese parece ser que o que contará para a legitimação será o mesmo que o que valerá para a justificação. É por isso que o consenso é aquilo que tanto garante a legitimidade do uso do poder político quanto assegura a validade da norma (RAWLS, 1971, p. 580; RAWLS, 1999, p. 508; RAWLS, 1996, p. $136)^{13}$. Assim, a tarefa real de justificar uma concepção de justiça não é primordialmente um problema epistemológico:

A busca por fundamentos razoáveis para alcançar um acordo enraizado em nossas concepções de nós mesmos e em nossa relação com a sociedade substitui a busca pela verdade moral interpretada como fixada por uma ordem anterior e independente de objetos e relações, naturais ou divinas, uma ordem aparte e distante de como nós nos concebemos. (RAWLS, 1980, p. 306) ${ }^{14}$. 
Seria esse modelo de justificação arbitrário? Penso que não. Isso porque os princípios de justiça aceitos com base em nossas convicções morais mais profundas podem ser testados tanto por um procedimento formal de simetria na deliberação quanto por um procedimento pragmático de estabilidade e legitimidade. É verdade que não se conta com um critério último que pairaria fora do mundo; entretanto, a norma está sendo estipulada porvalores sociais que vem obtendo aceitação nas próprias práticas e são validados por procedimentos. A normatividade é factual-procedimental. A concepção alternativa de Estlund, por sua vez, diz que acabaria com a arbitrariedade em razão do uso de uma concepção mínima de verdade. Será mesmo? Vejamos o exemplo dado por ele: se todos podem aceitar que assassinar é errado, então, "assassinar é errado" é verdadeiro no sentido mínimo exigido pelo liberalismo político. Qual a diferença em relação à justiça como equidade até aqui? Parece que nenhuma, uma vez que o argumento é o mesmo: se todos podem aceitar que a intolerância religiosa e a discriminação racial são injustas com uso do(s) procedimento(s), então, a "intolerância religiosa" e a "discriminação racial" são injustas e, sendo injustas, não devem ser praticadas ${ }^{15}$. Note-se que esta estratégia procedimental parece possuir o mesmo peso que uma concepção minimalista de verdade. Isso porque uma concepção minimalista não pressupõe a existência de uma ordem de coisas independente dos sujeitos que serviriam de critério para saber se o dito corresponderia ou não a essa ordem de coisas; entretanto, possibilita que o juízo moral seja tomado como objetivo. É esta concepção de verdade representacionalista que está sendo recusada por Rawls e não uma concepção deflacionada de verdade que, inclusive, é adequada a um modelo coerentista e pragmatista de justificação ${ }^{16}$. Penso que não é muito elucidativo uma inflação demasiadadessa distinção entre o razoável e o verdadeiro, uma vez que a razoabilidade pode ser tomada como uma verdade prática, isto é, como uma convergência prática social. Se Estlund parece também recusar essa concepção tradicional de verdade, não compreendo, então, qual a forte distinção entre o que ele está propondo e o que é defendido por Rawls. E assim, porque apenas o modelo rawlsiano seria arbitrário? Não seria essa posição ela própria arbitrária?

E o que dizer da outra objeção a respeito da exigência da razoabilidade do agente moral? Seria ela excessiva e ineficaz, uma vez que o agente moral comum parece não possuir esse critério metajustificatório para a 
validação de suas crenças, isto é, crenças de segunda ordem? Retomemos a explicação do que é razoabilidade para Rawls com a finalidade de identificar seu conteúdo específico. Com isso em mãos, pretendo mostrar que essa exigência não é demasiada, mas, ao contrário, é uma exigência comum que se faz a qualquer cidadão de uma sociedade democrática contemporânea.

Em primeiro lugar, razoabilidade é uma disposição para propor e cumprir os termos equitativos de cooperação e, sendo assim, é compreendida como uma faculdade moral que capacita o agente a propor e depois motivar-se a agir em conformidade com os termos equitativos de cooperação por seu valor intrínseco. Isto quer dizer que a razoabilidade é uma virtude social que é pressuposta pela justiça como equidade (RAWLS, 1996, p. 54). Explicando mais detalhadamente essa virtude moral social, temos que a razoabilidade: (i) é parte da sensibilidade moral; (ii) está conectada com a ideia de reciprocidade, que é intermediária entre o altruísmo e o egoísmo; (iii) não é derivada da racionalidade; (iv) é pública, de forma que garante a igualdade entre as pessoas no âmbito do reconhecimento social (RAWLS, 1996, p. 48-54).

Em segundo lugar, razoabilidade é a disposição para reconhecer os limites do juízo e da razão e aceitar suas consequências para o uso público da razão na condução do exercício legítimo do poder político em um regime democrático constitucional (RAWLS, 1996, p. 54). Já vimos que isso implicará em reconhecer o (i) fato do pluralismo razoável, isto é, reconhecer como legítima a diversidade moral que obedece a restrição do razoável e o (ii) fato da opressão, que é a compreensão que só com um Estado forte e opressivo se garantiria a unidade moral. Essa é uma exigência intelectual, uma vez que o indivíduo deve compreender a realidade em que vive, identificando que nem toda a pessoa razoável defende a mesma doutrina abrangente e, logo, não é possível que todas essas doutrinas sejam verdadeiras. Também, isso implicará em endossar alguma forma de liberdade de consciência e autonomia de pensamento. Pode-se perceber, então, que esse reconhecimento dos limites do juízo é fundamental para a ideia democrática de tolerância. A esse respeito, é importante fazer referência a essa observação de Rawls:

Não é realístico - ou pior, isto desperta suspeita mútua e hostilidade

- supor que todas as nossas diferenças estão enraizadas apenas na 
ignorância e perversidade, ou ainda, em rivalidades pelo poder, status ou ganho econômico. (RAWLS, 1996, p. 58) ${ }^{17}$.

De posse desse conteúdo da razoabilidade, se pode agora tentar responder a objeção de Timmons, usando o seguinte argumento: não é uma exigência demasiada a um agente moral porque não é uma exigência demasiada a um cidadão de uma democracia constitucional, uma vez que o agente moral é um cidadão. É legítimo exigir que um cidadão aja de forma racional e razoável, isto é, que deva fazer uso de juízos, inferências e pensamento e, também, que aja a partir de um senso moral adequado. Um agente moral é uma pessoa. Uma pessoa tem capacidade de senso de justiça (razoabilidade) e concepção de bem (racionalidade). Isso quer dizer que os agentes devem ter essas duas capacidades (de pessoa) num grau mínimo que lhe permitam sercidadãos livres e iguais em um regime constitucional e, assim, a exigência é legítima (RAWLS, 1996, p. 61-62).

Quero chamar atenção para o seguinte fato: não há uma grande celeuma a respeito de serem demasiadas as exigências que se fazem aos cidadãos reais em comunidades reais. Vemos como legítimas as exigências de ter que obedecer às leis, como as encontradas na constituição, código penal, código civil e outros códigos socialmente reconhecidos. Se alguém estuprar ou sequestrar uma pessoa e for presa e acusada por esse ato, não servirá de desculpa o fato dela não saber que isso era proibido por lei. Nem no caso da pessoa não saber ler ou ter passado um período em coma. Isso quer dizer que exigimos dos cidadãos que eles obedeçam ao que a lei determina e, além disso, que eles se conduzam de certa forma moral, isto é, de certa forma imparcial ou que respeita a reciprocidade, que é o mesmo que dizer que os cidadãos devem ser civilizados, podendo conviver harmoniosamente com os outros. O que é isso senão exigir o reconhecimento dos limites dos juízos e da razão? Agora, se não é demasiado para os cidadãos comuns, por que seria uma exigência demasiada para o agente moral?

A crítica de Timmons é que a exigência do reconhecimento dos limites da razão implica no conhecimento de uma crença de segunda ordem que possibilitará a justificação das crenças de primeira ordem. Creio que isso seja um engano ao menos parcialmente, pois Rawls procura deixar claro que esse reconhecimento dos limites racionais não é uma posição 
cética, não implicando em um argumento cético sobre a limitação do conhecimento, pois, se não, o consenso sobreposto seria inviabilizado. Antes, é obtido por experiência histórica e não por um argumento de dúvida do conhecimento e da razão: "Essa dificuldade resulta da experiência histórica, dada por séculos de conflitos sobre crenças religiosas, filosóficas e morais" (RAWLS, 1996, p. 63). Isso não impede que alguns agentes possam ter uma crença epistemológica de segunda ordem, mas isso não é uma exigência para todo o agente moral. No geral, o agente deve ter um "saber como" ser razoável, não necessitando de um "saber que" a razoabilidade seja uma premissa verdadeira. Nada mais é do que um respeito tolerante aos valores defendidos pelas outras pessoas e isso se aprende mais com a história do que com a epistemologia. Então, seria demasiado exigir do cidadão algum conhecimento da história? Creio que não, da mesma forma que não seria demasiado exigir esse tipo de conhecimento do agente moral em razão dele mesmo ser um cidadão.

Mas, se as pessoas não forem efetivamente razoáveis, não seria ineficaz essa exigência? A isso respondo que o argumento central da justiça como equidade não requer que os agentes sejam de fatos razoáveis, mas que possam ser razoáveis. Dito de outra forma, a teoria moral rawlsiana pressupõe uma importante distinção entre 'competência e performance' e isso implica em dizer que a exigência da razoabilidade recai sobre essa capacidade moral e não sobre a real ação dos agentes ${ }^{18}$. Tudo o que a teoria de Rawls necessita é que os indivíduos possam agir razoavelmente, que possam escolher a partir do que seria uma posição de razoabilidade, mas não precisa contar com a ação real dos sujeitos. Para Rawls:

Agora se pode pensar inicialmente da filosofia moral (e eu ressalto a natureza provisória dessa concepção) como uma tentativa de descrever nossa capacidade moral, ou, no caso presente, se pode pensar uma teoria da justiça como descrevendo nosso senso de justiça. (RAWLS, 1971, p. 46; 1999, p. 41) ${ }^{19}$.

Para provar o argumento, basta mostrar que uma ou algumas pessoas são de fato razoáveis. Dessa forma, se pode perceber que a própria pesquisa de Deana Kuhn que é utilizada por Gaus prova o argumento central da justiça como equidade, uma vez que a investigação mostra que um pouco menos da metade dos sujeitos investigados agem de forma razoável, isto é, 
mostra que os sujeitos não são absolutistas em seus juízos cotidianos. Isso já é o bastante para se estipular que os agentes morais devem agir razoavelmente, uma vez que eles possuem a capacidade para agir dessa forma moral, pressuposto tal que se pode comprovar ao mostrar que pessoas reais de fato agem razoavelmente.

\section{IV}

Nessa parte final do texto, eu quero ressaltar qual o ganho que podemos ter ao usar a razoabilidade ao invés da verdade como critério objetivo para a determinação do que é o justo.Vejamos isso a partir da forma como a justiça como equidade estabelece os preceitos da discussão razoável. Sendo uma pessoa razoável aquela que tem consciência dos limites da razão e do juízo, ela reconhecerá certos preceitos para orientar a deliberação e a discussão no âmbito público. Esses preceitos de razoabilidade são: (i) disposição para alcançar o acordo razoável na discussão política; (ii) estabilidade psicológica para encontrar desacordos substanciais sobre questões básicas (questões constitucionais e de justiça básica); (iii) disposição para creditar aos outros uma certa boa fé, aceitando a diversidade (RAWLS, 1989, p. 478-479). O que isso mostra? Que uma concepção de justiça que está sendo construída a partir do critério da razoabilidade ou aceitabilidade (preferencialmente do que ao critério de verdade), não precisa estar comprometida nem com um realismo ontológico, nem com um fundacionalismo epistemológico e nem mesmo com um representacionalismo semântico. Com o uso de um critério de verdade não mínimo temos um modelo de filosofia moral e política que se baseia na descoberta de determinadas premissas que fundamentarão os princípios morais, sendo essa descoberta dada por um indivíduo a partir de sua razão privada, não havendo a valorização da história para essa deliberação individual em razão do teste final ser dado por correspondência. Isso implicará em dualismo, dogmatismo, assimetria e input solipsista. Alternativamente, com o uso do critério de razoabilidade, conseguimos superar os problemas epistemológicos anteriormente citados. Isso em razão, principalmente, desse modelo coerentista e pragmatista fazer uso de premissas que podem ser publicamente reconhecidas a partir de uma razão coletiva, o que traz por 
consequência a valorização da história nessa deliberação social. Veja-se que o problema do input solipsista é resolvido, uma vez que a determinação das normas morais será dada por um teste da coerência e da eficiência, com o respeito à reciprocidade. Note-se, também, o ganho desse modelo para se pensar a respeito da responsabilidade moral do agente. No modelo de descoberta, a ação moral verdadeiramente responsável poderia pressupor uma escolha verdadeira pelo o que se é (o tipo de pessoa que se é); e como as pessoas não podem escolher verdadeiramente como são, elas não seriam verdadeiramente responsáveis por suas ações ${ }^{20}$. Com o modelo de reconhecimento, como é o modelo coerentista de Rawls, podemos substituir o 'verdadeiramente' pelo 'razoavelmente' e o 'como se é pelo 'o que se pode ser' e, assim, teríamos:

(i) A ação moral razoavelmente responsável pressupõe uma escolha razoavelmente responsável pelo o que se pode ser;

(ii) As pessoas podem escolher razoavelmente como podem ser;

(iii) Logo, as pessoas são razoavelmente responsáveis por suas ações.

O termo 'razoavelmente' significa aqui que se seguiu os preceitos da discussão razoável, o que implica tomar o razoável pelo o que tem aceitabilidade social. Assim, ser responsável por uma ação não é ser responsável nem pelo que se é e nem por todas as suas consequências. Antes, é uma responsabilidade que está centrada na deliberação do agente que pesa razões e escolhe a melhor alternativa. Por isso, o agente pode ser responsabilizado pelo tipo de pessoa que ele pode ser, pois tem capacidade de agir de forma moral (senso de justiça) e racional (concepção de bem) e, assim, sua ação pode ser responsabilizada. Não se trata de uma responsabilidade última, é claro, mas de uma concepção exequível de responsabilidade moral, que está circunscrita a um âmbito de pluralismo moral razoável. E assim, toda a dramatização a respeito da perda da normatividade da justiça como equidade, em razão da ausência do critério de verdade, creio que se mostra excessiva.

${ }^{1} \mathrm{O}$ equilíbrio reflexivo é o método por excelência da justiça como equidade, o que já revela sua filiação a uma epistemologia coerentista do tipo holística, isto por que o que será exigido 
para a justificação de uma crença moral será que ela deve ser coerente não apenas com outra crença, mas com um conjunto coerente de crenças. No artigo "Reply to Habermas", Rawls faz referência ao equilíbrio reflexivo pleno (full) como um ponto ao infinito que nós nunca poderemos alcançar, mas que podemos chegar próximos através da discussão em que nossos (i) ideais, (ii) princípios e (iii) juízos pareçam mais razoáveis para nós, apresentando como característica central a intersubjetividade: "The overall criterion of the reasonable is general and wide reflective equilibrium; (...). Reflective equilibrium resembles his test in this respect: it is a point at infinity we can never reach, though we may get closer to it in the sense that though discussion, our ideals, principles, and judgments seem more reasonable to us and we regard them as better founded than they were before." (RAWLS, 1995, p. 384-385). "Thus citizens have achieved general and wide, or what we may refer to as full, reflective equilibrium. (The adjective 'full' we reserve for features as realized in a well-ordered society)". (RAWLS, 2001, p. 31). O uso do equilíbrio reflexivo geral, ou consenso sobreposto, também parece apontar para uma filiação a uma tradição pragmatista de justificação, que conecta de forma forte a justificação com a questão da legitimação (detalharei esse ponto mais adiante). Creio que podemos afirmar, sem um grande receio de errar o alvo, que o método nada mais é do que um teste de aceitabilidade pessoal/social, teste que é tanto em primeira (equilíbrio reflexivo amplo), quanto em terceira pessoa (equilíbrio reflexivo geral). A sua função é mostrar para nós os valores morais que nós já aceitamos de um ponto de vista social e orientar nossa deliberação moral nessa mesma direção.

2 "We collect such settled convictions as the belief in religious toleration and the rejection of slavery and try to organize the basic ideas and principles implicit in these convictions into a coherent political conception of justice. These convictions are provisional fixed points that it seems any reasonable conception must account for. We start, then, by looking to the public culture itself as the shared fund of implicitly recognized basic ideas and principles". (RAWLS, 1996, p. 8).

${ }^{3}$ Essa referência à exigência de razoabilidade se dá a partir dos cinco fatos gerais que são tomados como pontos de partida da justiça como equidade: (i) pluralismo razoável, (ii) fato da opressão, (iii) apoio ao regime democrático, (iv) ideias intuitivas da cultura pública, (v) revisibilidade das crenças. A esses fatos gerais se adicionam duas ideias normativas de (i) sociedade cooperativa e (ii) pessoas livres e iguais.Ver RAWLS, 1989, p. 474-478 e RAWLS, 1996, p. 48-58.

4 "The first basic aspect of the reasonable, then, is the willingness to propose fair terms of cooperation and to abide by them provided others do. The second basic aspect, as I review now, is the willingness to recognize the burdens of judgment and to accept their consequences for the use of public reason in directing the legitimate exercise of political power in a constitutional regime". (RAWLS, 1996, p. 54). Um esclarecimento para a tradução da expressão "burdens of judgment". O termo "burden" é melhor traduzido como "carga" ou "sobrecarga". O problema é que a expressão "sobrecarga do juízo" diz muito pouco. Dessa forma, usarei preferencialmente "limites do juízo" e "limites da razão" para "burdens of reason", pois creio que melhor expressa a ideia do texto, que é a do reconhecimento de que a razão não é capaz de encontrar uma justificação última para os juízos morais dos cidadãos.

${ }^{5}$ Os procedimentos da posição original e equilíbrio reflexivo são explicados detalhadamente em RAWLS, 1999, \4 e 9. Importante observar que esse procedimento de construção e teste não faz uso de um processo inferencial de conhecimento em que os princípios de justiça

doispontos, Curitiba, São Carlos, vol. 10, n. 1, p.37-59, abril, 2013 
seriam deduzidos de premissas autoevidentes. Alternativamente, a justificação é tomada como uma questão de apoio mútuo de várias considerações, todas elas encaixando em conjunto numa visão coerente. Ver RAWLS, 1999, p. 19. Por outro lado, a função do procedimento do consenso sobreposto é garantir a estabilidade social pelas razões corretas, de forma que pessoas que professam doutrinas abrangentes razoáveis podem endossar uma mesma concepção política de justiça, cada qual a partir de seu próprio ponto de vista.Ver RAWLS, 1996, p. 134.

${ }^{6}$ Sintetizando, o argumento de Raz no artigo "The Case of Epistemic Abstinence" é o seguinte: como a justiça como equidade tem uma tarefa prática de possibilitar estabilidade social e não teórica, tendo um fundamento fraco nos valores morais comuns dados pela tradição, sendo tomada como autossuficiente e, consequentemente, sofrendo de abstinência epistêmica, mesmo se falsa a teoria poderia ser aceita se realizasse seu papel prático. Diz que se evitarmos a abstinência epistêmica nós reconheceríamos que o papel prático dos princípios de justiça em alcançar o consenso sobreposto que garante unidade e estabilidade seria uma questão teórica sobre a verdade dos princípios. Ver RAZ, 1990, p. 16. Isto significa que para Raz, justificação está necessariamente conectada a uma ideia de verdade. Para Estlund, diferentemente, como apontado no final de seu artigo, determinadas obrigações podem estar fundadas na sua legitimidade e não na verdade. Em outras palavras, ele avalia que a força coercitiva do poder político é legítima com base em sua aceitabilidade/razoabilidade, isto é, com base na aceitação dessas regras por parte de pessoas razoáveis e racionais, o que revela que ele está distinguindo justificação de verdade e a aproximando da legitimação. A discordância em relação a Rawls se dá por ele achar que essa proposta falhará a menos que sua doutrina fundamental, o critério de aceitabilidade, seja ao menos aproximadamente verdadeira.Ver ESTLUND, 1998, p. 275.

${ }^{7}$ Veja-se que Estlund e Raz não estão isolados nessa posição crítica que também é compartilhada por vários outros autores, como é o caso de Alan Thomas. Ele faz uma interpretação muito semelhante à de Estlund, reivindicando que o princípio da restrição ao razoável para a justificação/legitimação deve ele próprio ser verdadeiro e não apenas razoável. Em suas próprias palavras: "Precisamos procurar por verdades independentes em uma moralidade política sui generis para melhorar o sentido geral dessa posição" (THOMAS, 2010, p. 282). A esse respeito, ver, também, o artigo de Gardiner: "Rawls on Truth and Toleration" (GARDINER, 1988, p. 103-111).

${ }^{8}$ Esta crítica esta situada em uma proposta mais ampla de defender uma justificação moral contextualista, defendendo um contextualismo estrutural. É nessa perspectiva que ele investigará sobre um ideal realístico de responsabilidade epistêmica. Ver TIMMONS, 2004, p. 178-246.

${ }^{9}$ Este parece ser o argumento central desenvolvido por Marilyn Friedman no artigo "John Rawls and the Political Coercion of Unreasonable People". Ela defende que as pessoas geralmente não são razoáveis em razão de terem crescido sob instituições injustas ao invés de sob instituições livres como as postuladas no ideal de sociedade bem-ordenada de Rawls. Ver FRIEDMAN, 2000, p. 16-19.

${ }^{10}$ Gaus cita a pesquisa de Deanna Kuhn para mostrar a inviabilidade de contar com o reconhecimento dos limites dos juízos para a justificação, uma vez que ela mostra que ao menos metade dos sujeitos investigados (entre a adolescência até a idade madura) se revelaram absolutistas em seus juízos. O estudo coordenado por Kuhn revelou que mais da metade das pessoas

doispontos, Curitiba, São Carlos, vol. 10, n. 1, p.37-59, abril, 2013 
investigadas que deviam explicar as causa do crime, desemprego e falha na escola, viam suas crenças como corretas e nunca como erradas. Esse estudo está documentado em The Skills of Argument.Ver GAUS, 1996, p. 134-135.

11 "Observe that here being reasonable is not an epistemological idea (though it has epistemological elements). Rather, it is part of a political ideal of democratic citizenship that includes the idea of public reason". (RAWLS, 1996, p. 62)

${ }^{12}$ A passagem inteira é a seguinte: "We hope that by doing this we can, in working political practice, firmly ground the constitutional essentials in those political values alone, and that these values will provide a satisfactory shared basis of public justification." (RAWLS, 1989, p. 485).

13 Maffettone fala acertadamente de uma "conexão estrutural entre dois tipos de consenso - entre o liberalismo e a democracia e entre justificação e legitimação" (MAFFETTONE, 2010, p. 249). A tese de Maffettone é que se pode responder a esse tipo de crítica a respeito da pretensa fraqueza do critério de razoabilidade ressaltando que justificação e legitimação estão conectadas na forma que Rawls pensa a justificação das normas, conectando um consenso ideal com um consenso real. Ele explica esta complementaridade entre justificação e legitimação na forma de um ‘institucionalismo normativo’ (MAFFETTONE, 2010, p. 23). Ver a seminal reflexão sobre a centralidade do critério de razoabilidade na justiça como equidade em MAFFETTONE, 2010, p. 237-249. Numa direção similar, Laden ressalta um projeto alternativo da justiça como equidade, destacando quatro importantes elementos. Para nossa discussão específica, chamo atenção para os elementos 3 e 4: (3) seus argumentos são estabelecidos para servir de justificação pública preferencialmente a que sejamtomados como deduções a partir de premissas sobre a natureza humana ou racionalidade e (4) a ideia central e o ponto mais alto de seu projeto é a ideia de razão pública e deliberação pública.Ver LADEN, 2003, p. 379. 14 "The search for reasonable grounds for reaching agreement rooted in our conception of ourselves and in our relation to society replaces the search for moral truth interpreted as fixed by a prior and independent order of objects and relations, whether natural or divine, an order apart and distinct from how we conceive of ourselves". (RAWLS, 1980, p. 306)

${ }^{15}$ Freeman também pensa que é possível aproximar o conceito de razoável com verdadeiro: "Rawls também acredita que a justiça como equidade é a concepção política mais razoável (ou verdadeira, se você quiser) e que ela está em uma melhor posição para encontrar o critério de reciprocidade e possibilitar uma base para a justificação pública requerida pelo princípio liberal de legitimidade".Ver FREEMAN, 2009, p. 230.

${ }^{16}$ Isso pode soar estranho, mas é precisamente isso que Rawls faz. Veja sua definição de justificação: "Preferencialmente, justificação é endereçada aos outros que discordam de nós e, dessa forma, deve sempre proceder de algum consenso, isto é, de premissas que nós e os outros reconhecemos publicamente como verdadeiras; ou melhor, que reconhecemos publicamente como aceitáveis para nós para o propósito de estabelecer um acordo viável sobre questões fundamentais de justiça política." (RAWLS, 1985, p. 394).Veja-se que aqui "premissas verdadeiras" e "premissas aceitáveis" estão sendo tomadas como intercambiáveis. A substituição do termo "verdadeiras" por "aceitáveis" parece ter a função específica de ressaltar que não se fará uso de uma epistemologia representacionalista e uma ontologia realista.

doispontos, Curitiba, São Carlos, vol. 10, n. 1, p.37-59, abril, 2013 
17 "It is unrealistic - or worse, it arouses mutual suspicion and hostility - to suppose that all our differences are rooted solely in ignorance and perversity, or else in the rivalries for power, status, or economic gain". (RAWLS, 1996, p. 58).

${ }^{18}$ Estou fazendo uso de uma interessante abordagem de John Mikhail que interpretou a justiça como equidade como fazendo uso da hipótese de uma gramática moral universal, em que os seres humanos nascem com uma gramática moral, em analogia com a gramática linguística como postulada por Chomsky, analogia feita por Rawls em RAWLS, 1999, \ 9. Não quero me deter na abordagem naturalística feita por Mikhail, da qual eu tenho muitas reservas, mas ressaltar a importância da distinção que ele identifica na justiça como equidade. Mikhail defende que a distinção entre competência e performance, que é tão importante na teoria linguística de Chomsky, também é utilizada por Rawls, distinguindo o que é competência moral e performance moral. Para ele, a competência moral está associada ao conhecimento moral individual, sendo as condições mentais do agente para ação, enquanto que performance moral está associada a como o conhecimento moral é usado, isto é, com o comportamento moral dos indivíduos. Ver MIKHAIL, 2011, p. 17-19.

19 "Now one may think of moral philosophy at first (and I stress the provisional nature of this view) as the attempt to describe our moral capacity; or, in the present case, on may regard a theory of justice as describing our sense of justice". (RAWLS, 1971, p. 46; 1999, p. 41).

20 Estou pensando em uma compreensão de responsabilidade moral como a de Galen Strawson, que conecta em última instância responsabilidade da ação com uma escolha verdadeira sobre o tipo de pessoa. que se é (autodeterminação). Ele prova a impossibilidade da responsabilidade moral com o seguinte argumento básico: (i) A ação moral verdadeiramente responsável pressupõe uma escolha verdadeiramente responsável pelo que se é (o tipo de pessoa que se é); (ii) As pessoas não podem escolher verdadeiramente pelo que são (não podem se autodeterminar); (iii) Logo, as pessoas não são verdadeiramente responsáveis por suas ações. Ver STRAWSON, 1994, p. 6-7.

\section{Referências bibliográficas} 1980. Kantian Constructivism in Moral Theory. In: Collected Papers, p. 303-358.

1985. Justice as Fairness: Political not Metaphysical. In: Collected Papers, p. 388-414.

1989. The Domain of the Political and Overlapping

Consensus. In: Collected Papers, p. 473-496.

1995. Reply to Habermas. In: Political Liberalism, p. 372-434. 1996. Political Liberalism. New York: Columbia University

Press. 
. 1999. A Theory of Justice. Revised Edition. Cambridge, Mass.:

Harvard University Press.

.1999a. Collected Papers. Ed. S. Freeman. Cambridge, Mass.:

Harvard University Press.

2001. Justice as Fairness: A Restatement. Ed. E. Kelly. Cambridge, Mass.: Harvard University Press.

ESTLUND, D. 1998. The Insularity of the Reasonable: Why Political Liberalism Must Admit the Truth. Ethics, v.Vol. 108, n.No. 2, p. 252-275.

FREEMAN, S. 2009. Justice and the Social Contract: Essays on Rawlsian Political Philosophy. New York: Oxford University Press.

FRIEDMAN, M. 2000. John Rawls and the Political Coercion of Unreasonable People. In: DAVION,Victoria; WOLF, Clark. The Idea of a Political Liberalism: Essays on Rawls. Oxford: Rowman \& Littlefield, p. 16-33.

GARDINER, B. 1988. Rawls on Truth and Toleration. The Philosophical Quarterly, vVol. 38, nNo. 150, p. 103-111.

GAUS, G. 1996. Justificatory Liberalism: An Essay on Epistemology and Political Theory. New York: Oxford University Press.

LADEN, A. S. 2003. The House That Jack Built:Thirty Years of Reading Rawls. Ethics, v.Vol. 113, n.No. 2, p. 367-390.

MAFFETTONE, S. 2010. Rawls: An Introduction. Cambridge: Polity Press.

MIKHAIL, J. 2011. Elements of Moral Cognition: Rawls' Linguistic Analogy and the Cognitive Science of Moral and Legal Judgment. New York: Cambridge University Press.

RAWLS, J. 1971. A Theory of Justice. Original Edition. Cambridge, Mass.: Harvard University Press.

RAZ, J. 1990. Facing Diversity: The Case of Epistemic Abstinence. Philosophy and Public Affairs, v.Vol. 19, n.No. 1, p. 3-46. 
STRAWSON, G. 1994. The Impossibility of Moral Responsibility.

Philosophical Studies, v.Vol. 75, No.n. 1/2, p. 5-24.

THOMAS, A. 2010. Value and Context:The Nature of Moral and Political Knowledge. Oxford: Oxford University Press.

TIMMONS, M. 2004. Morality without Foundations: A Defense of Ethical Contextualism. New York: Oxford University Press. 